\title{
Steps to preventing Type 2 diabetes: exercise, walk more, or sit less?
}

\section{Catrine Tudor-Locke* and John M. Schuna Jr.}

Walking Behavior Laboratory, Population Sciences, Pennington Biomedical Research Center, Baton Rouge, LA, USA

Edited by:

Catherine Chan, University of Alberta,

Canada

Reviewed by:

Shinichi Oikawa, Nippon Medical

School, Japan

Undurti N. Das, UND Life Sciences, USA

\section{*Correspondence:}

Catrine Tudor-Locke, Walking Behavior Laboratory, Pennington Biomedical

Research Center, 6400 Perkins Road, Baton Rouge, LA 70808, USA.

e-mail: tudor-locke@pbrc.edu
Accumulated evidence supports the promotion of structured exercise for treating prediabetes and preventing Type 2 diabetes. Unfortunately, contemporary societal changes in lifestyle behaviors (occupational, domestic, transportation, and leisure-time) have resulted in a notable widespread deficiency of non-exercise physical activity (e.g., ambulatory activity undertaken outside the context of purposeful exercise) that has been simultaneously exchanged for an excess in sedentary behaviors (e.g., desk work, labor saving devices, motor vehicle travel, and screen-based leisure-time pursuits). It is possible that the known beneficial effects of more structured forms of exercise are attenuated or otherwise undermined against this backdrop of normalized and ubiquitous slothful living. Although public health guidelines have traditionally focused on promoting a detailed exercise prescription, it is evident that the emergent need is to revise and expand the message to address this insidious and deleterious lifestyle shift. Specifically, we recommend that adults avoid averaging $<5,000$ steps/day and strive to average $\geq 7,500$ steps/day, of which $\geq 3,000$ steps (representing at least $30 \mathrm{~min}$ ) should be taken at a cadence $\geq 100 \mathrm{steps} / \mathrm{min}$. They should also practice regularly breaking up extended bouts of sitting with ambulatory activity. Simply put, we must consider advocating a whole message to "walk more, sit less, and exercise."

Keywords: walking, exercise therapy, sedentary lifestyle, training, guidelines

\section{INTRODUCTION}

Prediabetes, a state when blood glucose is elevated, yet not high enough to be classified as overt diabetes, is precursory to the development of Type 2 diabetes (Tabak et al., 2012). The American Diabetes Association (ADA) defines prediabetes as having any one of the following: (1) an impaired fasting glucose (IFG) indicated by a fasting plasma glucose (FPG) of $5.6-6.9 \mathrm{mmol} / \mathrm{L}$ without impaired glucose tolerance (IGT); (2) IGT, defined as a FPG $<7 \mathrm{mmol} / \mathrm{L}$ and a $2 \mathrm{~h}$ oral glucose tolerance test plasma glucose concentration of 7.8-11.1 mmol/L; or (3) glycated hemoglobin A1c (HbA1c) of 5.7-6.4\% (American Diabetes Association, 2011). Based on analyses of FPG or HbAlc collected from 2005 to 2008 during the National Health and Nutrition Examination Survey (NHANES), $35 \%$ of U.S. adults aged 20 years or older, and $50 \%$ of those aged 65 years or older, had prediabetes (Centers for Disease Control and Prevention (CDC), 2011). Applied to 2010 population data, this translates to an estimated 79 million prediabetic adults within the U.S. (Centers for Disease Control and Prevention (CDC), 2011). This is alarming as it is estimated that up to $70 \%$ of those with prediabetes will eventually develop Type 2 diabetes (Nathan et al., 2007). In an effort to address this public health issue, diabetes prevention programs (DPP; Eriksson and Lindgarde, 1991; Pan et al., 1997; The Diabetes Prevention Program Research Group, 1999; Uusitupa et al., 2000; Ramachandran et al., 2006) have attempted to elicit favorable changes in modifiable risk factors associated with prediabetes and Type 2 diabetes. Physical activity represents one risk factor (Hu et al., 1999, 2003b) that can be considered a logical primary target for modification in intervention research.
Physical activity recommendations for Type 2 diabetes prevention are congruent with general public health guidelines and call for a minimum of $150 \mathrm{~min} /$ week of moderate-to-vigorous physical activity (Physical Activity Guidelines Advisory Committee, 2008). These time-and-intensity based guidelines imply that this dose should be accumulated above and beyond some otherwise unquantified baseline level of non-exercise physical activity. However, it is precisely this volume of habitual behavior that has been most vulnerable to contemporary society-level energy-saving transitions evident in occupational tasks, domestic duties, transportation modes, and leisure-time preferences (Brownson et al., 2005; Church et al., 2011; Ng and Popkin, 2012). Time use studies clearly depict the dominating presence of sedentary behavior and light intensity activities during waking hours (Tudor-Locke et al., 2011b; Ng and Popkin, 2012). It is logical to forecast that public health guidelines will need future revisions to account for continued shifts toward an increasingly sedentary lifestyle ( $\mathrm{Ng}$ and Popkin, 2012) if basal levels of non-exercise physical activity continue to erode (Hamilton et al., 2007). The looming potentially negative impact of this sedentary lifestyle shift on the prevalence of prediabetes, and ultimately Type 2 diabetes, is critical. What is needed is a clear message that conveys the total amount of exercise and non-exercise physical activity necessary to elicit important health outcomes, including reducing early risk for prediabetes and ultimately Type 2 diabetes. This article will discuss the potential for an expanded message which not only emphasizes exercise, but also stresses the importance of more non-exercise physical activity (e.g., walking) and less sedentary time (e.g., sitting) as a complete public health strategy for improving the metabolic profile 
of individuals with prediabetes. To begin, we clarify terms used repeatedly herein.

\section{PHYSICAL ACTIVITY VS. ENERGY EXPENDITURE}

The term "physical activity" was defined by Caspersen et al. (1985) as "any bodily movement produced by the skeletal muscles that results in energy expenditure." This definition intentionally captured the broadest spectrum of human movement unrestricted in terms of duration, intensity, or frequency. In contrast, "energy expenditure," the metabolic cost of living, is shaped by sex, age, and body mass, and includes contributions from resting metabolic rate, the thermic effect of feeding, and the metabolic costs of movement (Lamonte and Ainsworth, 2001).

Day-to-day variability in energy expenditure within individuals is primarily the result of differences in physical activity behaviors (Westerterp, 2008), whereas between-individual variability in energy expenditure is largely influenced by differences in body mass (Masse et al., 2004). Since energy expenditure is related to, but not synonymous with physical activity, measures of energy expenditure can only be considered indirect estimates of physical activity (i.e., movement) across individuals, even with adjustments for body mass (Masse et al., 2004). Within individuals, lowered energy expenditure following short-term reductions in physical activity promotes a positive energy balance and subsequent increases in intra-abdominal fat (Olsen et al., 2008). However, the potentially deleterious effects of reduced physical activity on the body's metabolic processes likely extend beyond the intrinsic obesitygenerating demerits of compromised energy balance (Hamilton et al., 2007).

\section{EXERCISE}

Exercise has been defined as a subset of physical activity that "is planned, structured, and purposive in the sense that improvement or maintenance of one or more components of physical fitness is an objective" (Caspersen et al., 1985). The American College of Sports Medicine (ACSM) published a series of position stands describing the recommended quantity (i.e., frequency in days/week, and duration in min/day and min/week) and quality (i.e., intensity in metabolic equivalents or METs; 1 MET being equivalent to $3.5 \mathrm{~mL}$ of $\mathrm{O}_{2}$ consumption per $\mathrm{kg}$ body weight per minute) of exercise necessary to develop and maintain fitness in healthy adults (American College of Sports Medicine, 1978, 1990, 1998; Garber et al., 2011). In regard to cardiorespiratory training, the most recent position stand states: "The ACSM recommends that most adults engage in moderate-intensity cardiorespiratory exercise training for $\geq 30 \mathrm{~min} /$ day on $\geq 5$ days/week for a total of $\geq 150 \mathrm{~min} /$ week, vigorous-intensity cardiorespiratory exercise training for $\geq 20 \mathrm{~min} /$ day on $\geq 3$ days/week ( $\geq 75 \mathrm{~min} /$ week), or a combination of moderate- and vigorousintensity exercise to achieve a total energy expenditure of $\geq 500$ $1000 \mathrm{MET} / \mathrm{min} /$ week." This recommendation is congruent with the first U.S. Physical Activity Guidelines for Americans (Physical Activity Guidelines Advisory Committee, 2008) published in 2008: "For substantial health benefits, adults should do at least $150 \mathrm{~min}$ ( $2 \mathrm{~h}$ and $30 \mathrm{~min}$ ) a week of moderate-intensity, or $75 \mathrm{~min}$ ( $1 \mathrm{~h}$ and $15 \mathrm{~min}$ ) a week of vigorous-intensity aerobic physical activity, or an equivalent combination of moderate- and vigorous-intensity aerobic activity. Aerobic activity should be performed in episodes of at least $10 \mathrm{~min}$, and preferably, it should be spread throughout the week."

Chronic moderate and vigorous aerobic exercise (612 months) reduces insulin resistance (Houmard et al., 2004; Evans et al., 2005; Bajpeyi et al., 2009). However, evidence suggests that the duration of exercise is more important than intensity for eliciting favorable responses in insulin action (Houmard et al., 2004). Regular training enhances skeletal muscles' responsiveness to insulin by increasing activity and/or expression of proteins involved in insulin signaling and glucose metabolism (ChristRoberts et al., 2004; O'Gorman et al., 2006; Wang et al., 2009). Fat oxidation also plays a role in improved insulin action and aerobic exercise increases skeletal muscles' lipid storage and fat oxidation capacity (Duncan et al., 2003; Goodpaster et al., 2003; Pruchnic et al., 2004; Kelley and Kelley, 2007).

In addition to the favorable metabolic effects associated with regular exercise, epidemiological data from large prospective cohort studies indicate that moderate exercise, such as walking, and more vigorous activities, protects against the development of Type 2 diabetes (Helmrich et al., 1991; Manson et al., 1991; Hu et al., 1999). A synthesis of results from four cohort studies (Helmrich et al., 1991; Hu et al., 1999, 2001; Weinstein et al., 2004) indicates that brisk walking for at least $150 \mathrm{~min} /$ week, when compared to minimal amounts of weekly walking, significantly lowers risk for Type 2 diabetes [relative risk $=0.70$ (95\% CI 0.58-0.84); Figure 1, left panel; Jeon et al., 2007]. Moreover, evidence suggests that incrementally higher amounts of exercise provide greater protective benefits against Type 2 diabetes (Hu et al., 1999).

Among individuals already at risk for Type 2 diabetes, several randomized-controlled trials provide further evidence supporting the beneficial role of exercise (Pan et al., 1997; Tuomilehto et al., 2001; Knowler et al., 2002). As an example, the U.S. DPP reported that diabetes incidence after nearly 3 years of follow-up was $58 \%$ lower among participants at risk for Type 2 diabetes enrolled in a "lifestyle" intervention group (including weight loss, diet, and moderate-intensity exercise for at least $150 \mathrm{~min} /$ week) than those enrolled in a control group, and 39\% lower than those enrolled in a "drug" treatment group (prescribed metformin; Knowler et al., 2002). Unfortunately, objectively monitored data indicates that $<10 \%$ of the U.S. adult population exercises at this amount and intensity (Troiano et al., 2008; Tucker et al., 2011). However, associations between sedentary behavior and mortality from all causes and cardiovascular disease are independent of exercise (i.e., leisure-time physical activity; Katzmarzyk et al., 2009) and suggest that a "deficiency of non-exercise physical activity" (Hamilton et al., 2007) exchanged for excesses in sedentary behavior may diminish the beneficial effects of exercise. This threat should not be any different for people with prediabetes.

\section{NON-EXERCISE PHYSICAL ACTIVITY}

If "physical activity" represents the full spectrum of human movement, and "exercise" is a subcategory representing the higher end of this spectrum (Caspersen et al., 1985), then the remainder can be conceptualized as "non-exercise physical activity." Of all types of physical activity, public health and clinical practice efforts most commonly encourage walking (Siegel et al., 1995). "Walking for 


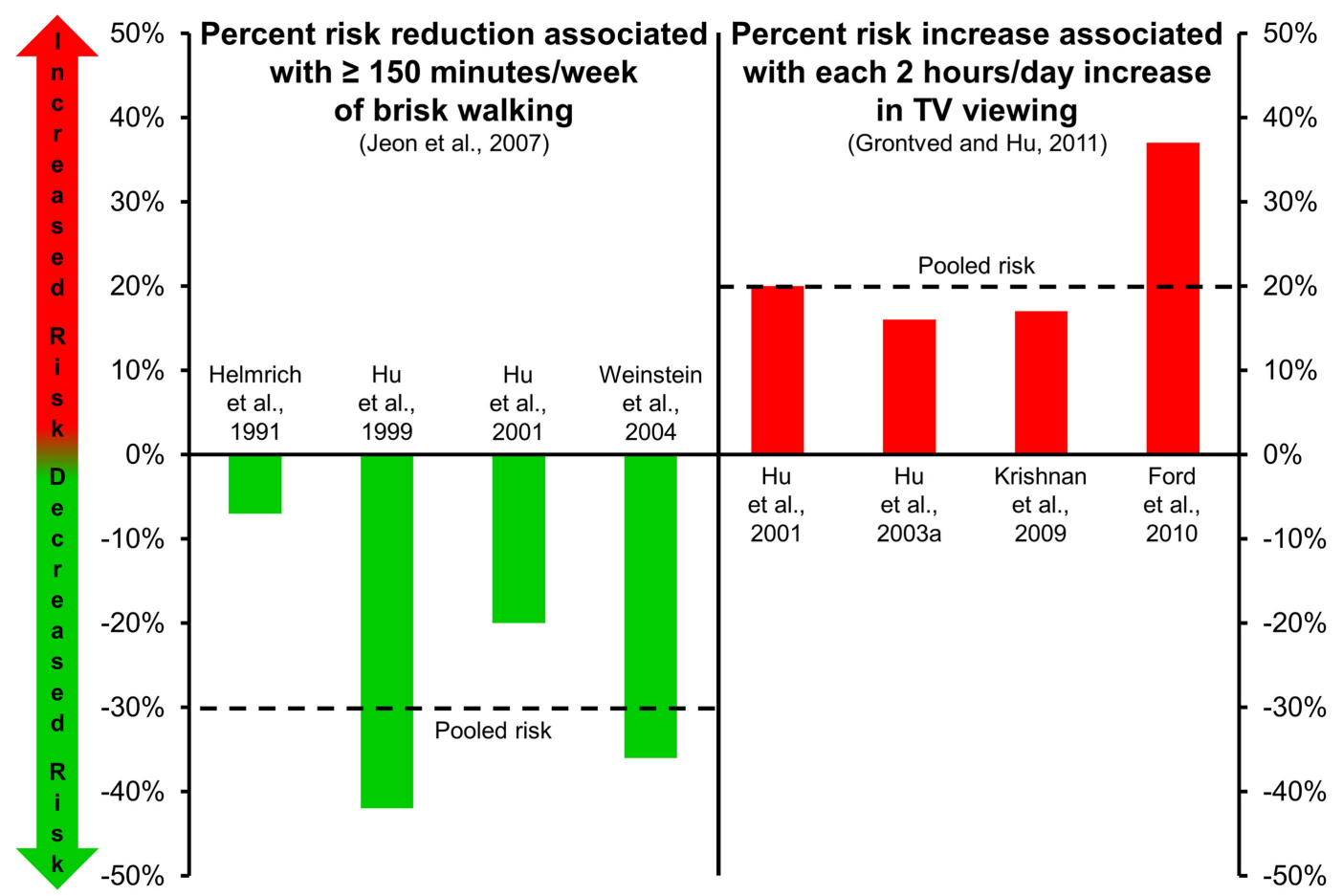

FIGURE 1 | Risk of type 2 diabetes associated with walking (left panel; Jeon et al., 2007) and TV viewing (right panel; Grontved and $\mathrm{Hu}$, 2011). Dashed lines in each panel represent the pooled risk among the studies included. Risk reduction associated with $\geq 150 \mathrm{~min} /$ week of brisk walking is in comparison to risk level associated with minimal amounts of weekly walking. exercise" is the most commonly reported form of exercise (Ham et al., 2009). But other forms of daily walking, including shopping, touring, and walking the dog (Tudor-Locke and Ham, 2008), to name but a few examples of other forms of walking behaviors, can more appropriately be classified as "non-exercise physical activity." Specific to incident diabetes, a prospective study of 37,828 women from the Women's Health Study found that self-reported walking for $2-3 \mathrm{~h} /$ week was associated with a $34 \%$ reduction in the incidence of Type 2 diabetes over almost 7 years of followup (Weinstein et al., 2004). Objectively measured walking (higher steps/day) has also been associated with lower levels of fasting glucose (Strath et al., 2007) and with reduced 5-year risk of incident dysglycemia (the effect was not fully mediated through reduced adiposity; Ponsonby et al., 2011). Interrupting extended bouts of sitting with light or moderate-intensity walking improves postprandial glucose and insulin levels in overweight/obese adults (Dunstan et al., 2012).

Unfortunately, there is mounting evidence that walking has eroded from our day-to-day lifestyle (Ng and Popkin, 2012). As an example, traditional Amish women and men take 14,00018,000 steps/day (Bassett et al., 2004) whereas recent U.S. estimates indicate typical modern adults take 5,900-6,900 steps/day (TudorLocke et al., 2004, 2009; Wyatt et al., 2005). Evidence is also emerging to suggest that the metabolic ramifications of this behavioral transition are not trivial. Mikus et al. (2012) studied healthy, active individuals who transitioned from averaging $>10,000$ steps/day to $<5,000$ steps/day for only 3 days to determine if this abrupt and temporary change in daily physical activity would modify postprandial and overall glycemic control as determined by continuous glucose monitors. Not surprisingly, the $>5,000$ steps/day reduction in ambulatory activity produced a $2.5 \mathrm{~h} /$ day increase in sitting time. After only 3 days of reduced ambulatory activity and increased sitting, significant increases in average glucose excursions were observed following meals.

\section{SEDENTARY BEHAVIORS}

Sedentary behaviors have been defined as those activities with a relatively low rate of energy expenditure (1-1.5 METs; Owen et al., 2000; Pate et al., 2008), a relative lack of movement as detected by objective monitoring devices (Matthews et al., 2008; Wong et al., 2011), and/or sitting postures (Kozey-Keadle et al., 2011; Owen et al., 2011). Even people who exercise may accumulate large amounts of sedentary behavior (Tremblay et al., 2010), and therefore exercise and sedentary behaviors are considered to be independent of each other (Tremblay et al., 2010). In contrast, sedentary behaviors appear to have systematically replaced non-exercise physical activity ( $\mathrm{Ng}$ and Popkin, 2012); there is an almost complete inverse association $(r=-0.96)$ between these two behaviors (Healy et al., 2007, 2008b; Tremblay et al., 2010). The current body of literature examining metabolic responses to bouts of sedentary behavior is limited. However, several studies have reported increases in insulin (up to 67\%) during a $2 \mathrm{~h}$ oral glucose tolerance test following extended periods of bed rest (Blanc et al., 2000; Hamburg et al., 2007). Plasma glucose levels may 
also significantly rise following extended periods of bed rest (Zorbas et al., 1999). Since bed rest studies represent an extreme case of enforced reclining/lying behavior, the generalizability of these findings to more common lifestyle-based patterns of prolonged sitting interspersed with natural movement can be questioned. However, recent research has shown that just a single day of prolonged sitting reduces insulin action (Stephens et al., 2011), and, as mentioned above, breaking up extended sitting time with short bouts of light or moderate-intensity walking may help moderate such effects and lower postprandial glucose and insulin levels (Dunstan et al., 2012).

Results from several large epidemiological studies indicate that higher amounts of sedentary time are associated with greater risks for obesity (Hu et al., 2003a), the metabolic syndrome (Ford et al., 2005; Sisson et al., 2009), and Type 2 diabetes (Hu et al., 2003a). Specifically, higher amounts of self-reported leisure-time sedentary behavior (e.g., screen-based behaviors including computer gaming, TV watching, etc.), and also usual sitting in the context of daily occupational/domestic work, is associated with a higher odds of the metabolic syndrome and individual cardiovascular disease risk factors (including elevated glucose; Sisson et al., 2009). Moreover, objectively measured sedentary time has been associated with clustered metabolic risk independent of time spent in moderateto-vigorous physical activity (Healy et al., 2008b). In particular, TV viewing is one of the most frequently reported sedentary behaviors (second only to eating and drinking) as captured in time use studies (Tudor-Locke et al., 2010). A meta-analysis (Grontved and $\mathrm{Hu}, 2011$ ) of four studies (Hu et al., 2001, 2003a; Krishnan et al., 2009; Ford et al., 2010) evaluating relationships between TV viewing and risk of Type 2 diabetes (175,938 individuals, 6428 incident cases during 1.1 million person-years of follow-up) reported that pooled relative risks were 1.20 per every $2 \mathrm{~h}$ /day of TV viewing (Figure 1, right panel). The estimated absolute risk difference per every $2 \mathrm{~h}$ of TV viewing per day was 176 cases of Type 2 diabetes per 100,000 individuals per year.

\section{THE WHOLE MESSAGE: WALK MORE, SIT LESS, AND EXERCISE}

It is apparent that a movement toward a "whole message" has been slowly evolving. As noted above, U.S. public health guidelines focus on promoting moderate-to-vigorous-intensity exercise, however, recent iterations do indeed acknowledge "more (activity) is better than none," especially in those who are considered inactive (Physical Activity Guidelines Advisory Committee, 2008). The ACSM included a steps/day recommendation in their recent update on the quantity and quality of exercise necessary to improve cardiorespiratory health outcomes (Garber et al., 2011). Finally, Canadian scientists have been the first to issue public health recommendations in regard to reducing sedentary behaviors (e.g., sitting), and replacing them with movement (most obviously walking behaviors; Tremblay et al., 2011, 2012). These messages appear to be also relevant to treating prediabetes and preventing Type 2 diabetes.

The whole message can be captured by advocating that adults "walk more, sit less, and exercise." Although the simplicity of this message is appealing, its lack of explicitly measureable parameters conveys only vague encouragement that cannot be easily tracked or otherwise evaluated. This is challenging, since as some may argue, at least in terms of walking behaviors, there maybe no apparent threshold effect: more is better, wherever your base is. Still, "walking more" can be broken down into daily frequency and accumulating greater amounts of time at higher cadences (steps/min; Tudor-Locke, in press). Specifically, we recommend that adults avoid days of taking $<5,000$ steps/day (Tudor-Locke et al., in press) and strive to average $\geq 7,500$ steps/day (Tudor-Locke et al., 2011a,c), of which $\geq 3,000$ steps (representing at least $30 \mathrm{~min}$; Tudor-Locke et al., 2005; Marshall et al., 2009) should be taken at a cadence $\geq 100$ steps/min (Tudor-Locke et al., 2005; Marshall et al., 2009; Beets et al., 2010; Abel et al., 2011; Rowe et al., 2011). They should also be encouraged to regularly break up extended bouts of sitting with ambulatory activity (Healy et al., 2008a; Dunstan et al., 2012). Reducing/interrupting sedentary behavior is compatible with "walking more" (Healy et al., 2007, 2008b; Tremblay et al., 2010) so a simple accounting of daily steps could be used to indirectly track sedentary behavior (Tudor-Locke et al., in press). A viable target sedentary behavior to limit/interrupt is prolonged television watching (i.e., >2 h/day; Sisson et al., 2009; Tudor-Locke et al., 2010; Grontved and Hu, 2011). However, since sedentary behaviors are ubiquitous in daily living (Matthews et al., 2008), there are ample opportunities to sit less, or perhaps more clearly, intermittently replace sitting by interjecting more bouts of walking throughout the day (Dunstan et al., 2012). Figure 2 presents a graphic representation of this message to "walk more, sit less, and exercise."

\section{SUMMARY}

In summary, prediabetes is on the rise, and with it comes the looming specter of Type 2 diabetes. Exercise is a recognized potent strategy for treating prediabetes and preventing Type 2 diabetes. Contemporary societal changes in lifestyle behaviors have resulted in a notable widespread deficiency of non-exercise physical activity exchanged for an excess in sedentary behaviors. It is possible that

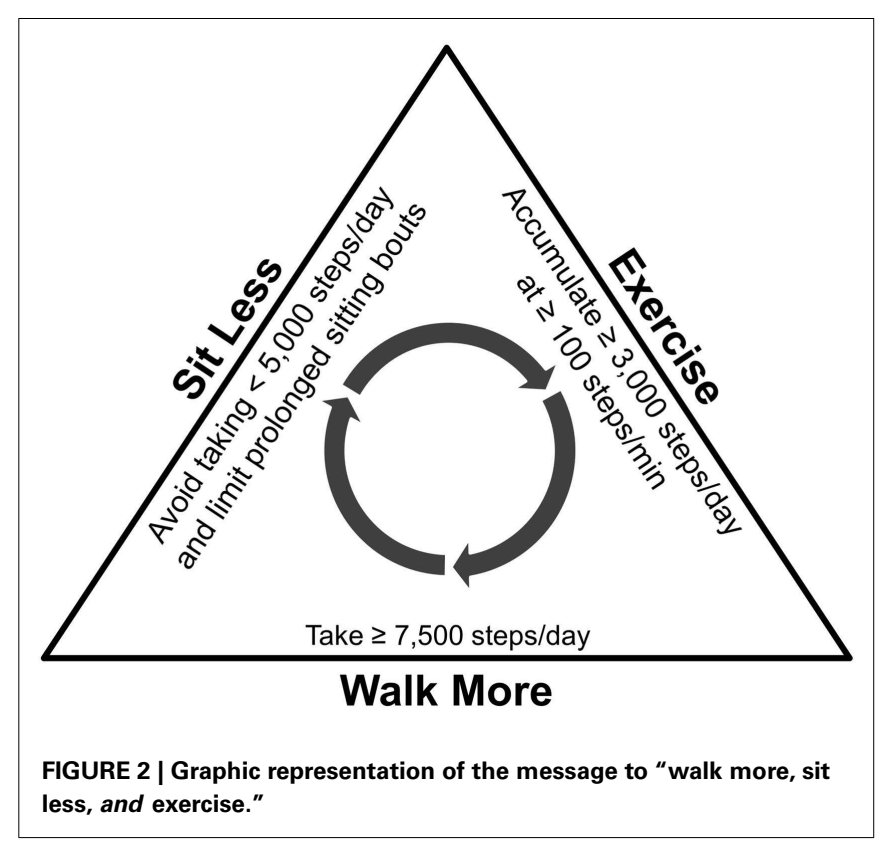


the known beneficial effects of exercise are undermined against this backdrop of normalized slothful living. Public health guidelines have historically focused on an exercise message, but it is

\section{REFERENCES}

Abel, M., Hannon, J., Mullineaux, D., and Beighle, A. (2011). Determination of step rate thresholds corresponding to physical activity classifications in adults. J. Phys. Act. Health 8, 45-51.

American College of Sports Medicine. (1978). American College of Sports Medicine position statement on the recommended quantity and quality of exercise for developing and maintaining fitness in healthy adults. Med. Sci. Sports 10, vii-x.

American College of Sports Medicine. (1990). American College of Sports Medicine position stand. The recommended quantity and quality of exercise for developing and maintaining cardiorespiratory and muscular fitness in healthy adults. Med. Sci. Sports Exerc. 22, 265-274.

American College of Sports Medicine. (1998). American College of Sports Medicine position stand. The recommended quantity and quality of exercise for developing and maintaining cardiorespiratory and muscular fitness, and flexibility in healthy adults. Med. Sci. Sports Exerc. 30, 975-991.

American Diabetes Association. (2011). Diagnosis and classification of diabetes mellitus. Diabetes Care 34(Suppl. 1), S62-S69.

Bajpeyi, S., Tanner, C. J., Slentz, C. A., Duscha, B. D., McCartney, J. S., Hickner, R. C., et al. (2009). Effect of exercise intensity and volume on persistence of insulin sensitivity during training cessation. J. Appl. Physiol. 106, 1079-1085.

Bassett, D. R., Schneider, P. L., and Huntington, G. E. (2004). Physical activity in an Old Order Amish community. Med. Sci. Sports Exerc. 36, 79-85.

Beets, M. W., Agiovlasitis, S., Fahs, C. A., Ranadive, S. M., and Fernhall, B. (2010). Adjusting step count recommendations for anthropometric variations in leg length. J. Sci. Med. Sport 13, 509-512.

Blanc, S., Normand, S., Pachiaudi, C., Fortrat, J. O., Laville, M., and Gharib, C. (2000). Fuel homeostasis during physical inactivity induced by bed rest. J. Clin. Endocrinol. Metab. 85, 2223-2233.

Brownson, R. C., Boehmer, T. K., and Luke, D. A. (2005). Declining rates of physical activity in the United States: what are the contributors? Annu. Rev. Public Health 26, 421-443.
Caspersen, C. J., Powell, K. E., and Christenson, G. M. (1985). Physical activity, exercise, and physical fitness: definitions and distinctions for healthrelated research. Public Health Rep. 100, 126-131.

Centers for Disease Control and Prevention (CDC). (2011). National Diabetes Fact Sheet: National Estimates and General Information on Diabetes and Prediabetes in the United States, 2011. Atlanta, GA: US Department of Health and Human Services, Centers for Disease Control and Prevention.

Christ-Roberts, C. Y., Pratipanawatr, T., Pratipanawatr, W., Berria, R., Belfort, R., Kashyap, S., et al. (2004). Exercise training increases glycogen synthase activity and GLUT4 expression but not insulin signaling in overweight nondiabetic and type 2 diabetic subjects. Metab. Clin. Exp. 53, 1233-1242.

Church, T. S., Thomas, D. M., TudorLocke, C., Katzmarzyk, P. T., Earnest, C. P., Rodarte, R. Q., et al. (2011). Trends over 5 decades in U.S. occupation-related physical activity and their associations with obesity. PLoS ONE 6, e19657. doi:10.1371/journal.pone.0019657

Duncan, G. E., Perri, M. G., Theriaque, D. W., Hutson, A. D., Eckel, R. H., and Stacpoole, P. W. (2003). Exercise training, without weight loss, increases insulin sensitivity and postheparin plasma lipase activity in previously sedentary adults. Diabetes Care 26, 557-562.

Dunstan, D. W., Kingwell, B. A., Larsen, R., Healy, G. N., Cerin, E., Hamilton, M. T., et al. (2012). Breaking up prolonged sitting reduces postprandial glucose and insulin responses. Diabetes Care 35, 976-983.

Eriksson, K. F., and Lindgarde, F. (1991). Prevention of type 2 (non-insulindependent) diabetes mellitus by diet and physical exercise. The 6-year Malmo feasibility study. Diabetologia 34, 891-898.

Evans, E. M., Racette, S. B., Peterson, L. R., Villareal, D. T., Greiwe, J. S. and Holloszy, J. O. (2005). Aerobic power and insulin action improve in response to endurance exercise training in healthy $77-87 \mathrm{yr}$ olds. $J$. Appl. Physiol. 98, 40-45.

Ford, E. S., Kohl, H. W. III, Mokdad, A. H., and Ajani, U. A. (2005). Sedentary behavior, physical activity, and

evident that the need to revise the message to reflect this lifestyle shift is necessary. Simply put, we must consider advocating a whole message to "walk more, sit less, and exercise."

the metabolic syndrome among U.S. adults. Obes. Res. 13, 608-614

Ford, E. S., Schulze, M. B., Kroger, J., Pischon, T., Bergmann, M. M., and Boeing, H. (2010). Television watching and incident diabetes: findings from the European Prospective Investigation into Cancer and Nutrition-Potsdam Study. $J$. Diabetes 2, 23-27.

Garber, C. E., Blissmer, B., Deschenes, M. R., Franklin, B. A., Lamonte, M. J., Lee, I. M., et al. (2011) American College of Sports Medicine position stand. Quantity and quality of exercise for developing and maintaining cardiorespiratory, musculoskeletal, and neuromotor fitness in apparently healthy adults: guidance for prescribing exercise. Med. Sci. Sports Exerc. 43 1334-1359.

Goodpaster, B. H., Katsiaras, A., and Kelley, D. E. (2003). Enhanced fat oxidation through physical activity is associated with improvements in insulin sensitivity in obesity. Diabetes 52, 2191-2197.

Grontved, A., and Hu, F. B. (2011). Television viewing and risk of type 2 diabetes, cardiovascular disease, and all-cause mortality: a meta-analysis. JAMA 305, 2448-2455.

Ham, S. A., Kruger, J., and TudorLocke, C. (2009). Participation by US adults in sports, exercise, and recreational physical activities. $J$. Phys. Act. Health 6, 1-10.

Hamburg, N. M., McMackin, C. J. Huang, A. L., Shenouda, S. M., Widlansky, M. E., Schulz, E., et al. (2007). Physical inactivity rapidly induces insulin resistance and microvascular dysfunction in healthy volunteers. Arterioscler. Thromb. Vasc. Biol. 27, 2650-2656.

Hamilton, M. T., Hamilton, D. G., and Zderic, T. W. (2007). Role of low energy expenditure and sitting in obesity, metabolic syndrome, type 2 diabetes, and cardiovascular disease. Diabetes 56 2655-2667.

Healy, G. N., Dunstan, D. W., Salmon, J., Cerin, E., Shaw, J. E., Zimmet, P. Z., et al. (2007). Objectively measured light-intensity physical activity is independently associated with 2-h plasma glucose. Diabetes Care 30, 1384-1389.

Healy, G. N., Dunstan, D. W., Salmon, J., Cerin, E., Shaw, J. E., Zimmet, P. Z., et al. (2008a). Breaks in sedentary time: beneficial associations with metabolic risk. Diabetes Care 31, 661-666.

Healy, G. N., Wijndaele, K., Dunstan, D. W., Shaw, J. E., Salmon, J., Zimmet, P. Z., et al. (2008b). Objectively measured sedentary time, physical activity, and metabolic risk: the Australian Diabetes, Obesity and Lifestyle Study (AusDiab). Diabetes Care 31, 369-371.

Helmrich, S. P., Ragland, D. R., Leung, R. W., and Paffenbarger, R. S. Jr. (1991). Physical activity and reduced occurrence of non-insulin-dependent diabetes mellitus. N. Engl. J. Med. 325, 147-152.

Houmard, J. A., Tanner, C. J., Slentz, C. A., Duscha, B. D., McCartney, J. S., and Kraus, W. E. (2004). Effect of the volume and intensity of exercise training on insulin sensitivity. $J$. Appl. Physiol. 96, 101-106.

Hu, F. B., Leitzmann, M. F., Stampfer, M. J., Colditz, G. A., Willett, W. C., and Rimm, E. B. (2001). Physical activity and television watching in relation to risk for type 2 diabetes mellitus in men. Arch. Intern. Med. 161, 1542-1548.

Hu, F. B., Li, T. Y., Colditz, G. A., Willett, W. C., and Manson, J. E. (2003a). Television watching and other sedentary behaviors in relation to risk of obesity and type 2 diabetes mellitus in women. JAMA 289, 1785-1791.

Hu, G., Qiao, Q., Silventoinen, K., Eriksson, J. G., Jousilahti, P., Lindstrom, J., et al. (2003b). Occupational, commuting, and leisure-time physical activity in relation to risk for Type 2 diabetes in middle-aged Finnish men and women. Diabetologia 46, 322-329.

Hu, F. B., Sigal, R. J., Rich-Edwards, J. W., Colditz, G. A., Solomon, C. G., Willett, W. C., et al. (1999). Walking compared with vigorous physical activity and risk of type 2 diabetes in women: a prospective study. JAMA 282, 1433-1439.

Jeon, C. Y., Lokken, R. P., Hu, F. B. and Van Dam, R. M. (2007). Physical activity of moderate intensity and risk of type 2 diabetes: a systematic review. Diabetes Care 30, 744-752.

Katzmarzyk, P. T., Church, T. S., Craig, C. L., and Bouchard, C. (2009). Sitting time and mortality from all causes, cardiovascular disease, and cancer. Med. Sci. Sports Exerc. 41, 998-1005. 
Kelley, G. A., and Kelley, K. S. (2007). Effects of aerobic exercise on lipids and lipoproteins in adults with type 2 diabetes: a meta-analysis of randomized-controlled trials. Public Health 121, 643-655.

Knowler, W. C., Barrett-Connor, E., Fowler, S. E., Hamman, R. F., Lachin, J. M., Walker, E. A., et al. (2002). Reduction in the incidence of type 2 diabetes with lifestyle intervention or metformin. N. Engl. J. Med. 346, 393-403.

Kozey-Keadle, S., Libertine, A., Lyden, K., Staudenmayer, J., and Freedson, P. S. (2011). Validation of wearable monitors for assessing sedentary behavior. Med. Sci. Sports Exerc. 43, 1561-1567.

Krishnan, S., Rosenberg, L., and Palmer, J. R. (2009). Physical activity and television watching in relation to risk of type 2 diabetes: the Black Women's Health Study. Am. J. Epidemiol. 169, 428-434.

Lamonte, M. J., and Ainsworth, B. E. (2001). Quantifying energy expenditure and physical activity in the context of dose response. Med. Sci. Sports Exerc. 33, S370-S378; discussion S419-S320.

Manson, J. E., Rimm, E. B., Stampfer, M. J., Colditz, G. A., Willett, W. C., Krolewski, A. S., et al. (1991). Physical activity and incidence of non-insulin-dependent diabetes mellitus in women. Lancet 338, 774-778.

Marshall, S. J., Levy, S. S., Tudor-Locke, C. E., Kolkhorst, F. W., Wooten, K. M., Ji, M., et al. (2009). Translating physical activity recommendations into a pedometer-based step goal: 3000 steps in 30 minutes. Am. J. Prev. Med. 36, 410-415.

Masse, L. C., Fulton, J. E., Watson, K. L., Mahar, M. T., Meyers, M. C., and Wong, W. W. (2004). Influence of body composition on physical activity validation studies using doubly labeled water. J. Appl. Physiol. 96, 1357-1364.

Matthews, C. E., Chen, K. Y., Freedson, P. S., Buchowski, M. S., Beech, B. M., Pate, R. R., et al. (2008). Amount of time spent in sedentary behaviors in the United States, 2003-2004. Am. J. Epidemiol. 167, 875-881.

Mikus, C. R., Oberlin, D. J., Libla, J. L., Taylor, A. M., Booth, F. W., and Thyfault, J. P. (2012). Lowering physical activity impairs glycemic control in healthy volunteers. Med. Sci. Sports Exerc. 44, 225-231.

Nathan, D. M., Davidson, M. B., Defronzo, R. A., Heine, R. J., Henry, R. R., Pratley, R., et al. (2007). Impaired fasting glucose and impaired glucose tolerance: implications for care. Diabetes Care 30, 753-759.

Ng, S. W., and Popkin, B. M. (2012). Time use and physical activity: a shift away from movement across the globe. Obes. Rev. 13, 659-680.

O'Gorman, D. J., Karlsson, H. K., McQuaid, S., Yousif, O., Rahman, Y., Gasparro, D., et al. (2006). Exercise training increases insulinstimulated glucose disposal and GLUT4 (SLC2A4) protein content in patients with type 2 diabetes. Diabetologia 49, 2983-2992.

Olsen, R. H., Krogh-Madsen, R., Thomsen, C., Booth, F. W., and Pedersen, B. K. (2008). Metabolic responses to reduced daily steps in healthy nonexercising men. JAMA 299, 1261-1263.

Owen, N., Leslie, E., Salmon, J., and Fotheringham, M. J. (2000). Environmental determinants of physical activity and sedentary behavior. Exerc. Sport Sci. Rev. 28, 153-158.

Owen, N., Sugiyama, T., Eakin, E. E., Gardiner, P. A., Tremblay, M. S., and Sallis, J. F. (2011). Adults' sedentary behavior determinants and interventions. Am. J. Prev. Med. 41, 189-196.

Pan, X. R., Li, G. W., Hu, Y. H., Wang, J. X., Yang, W. Y., An, Z. X., et al. (1997). Effects of diet and exercise in preventing NIDDM in people with impaired glucose tolerance. The Da Qing IGT and Diabetes Study. Diabetes Care 20, 537-544.

Pate, R. R., O’Neill, J. R., and Lobelo, F. (2008). The evolving definition of "sedentary." Exerc. Sport Sci. Rev. 36, 173-178.

Physical Activity Guidelines Advisory Committee. (2008). Physical Activity Guidelines Report, 2008. Washington, DC: U.S. Department of Health and Human Services.

Ponsonby, A. L., Sun, C., Ukoumunne, O. C., Pezic, A., Venn, A., Shaw, J. E., et al. (2011). Objectively measured physical activity and the subsequent risk of incident dysglycemia: the Australian Diabetes, Obesity and Lifestyle Study (AusDiab). Diabetes Care 34, 1497-1502.

Pruchnic, R., Katsiaras, A., He, J., Kelley, D. E., Winters, C., and Goodpaster, B. H. (2004). Exercise training increases intramyocellular lipid and oxidative capacity in older adults. Am. J. Physiol. Endocrinol. Metab. 287, E857-E862.

Ramachandran, A., Snehalatha, C., Mary, S., Mukesh, B., Bhaskar, A. D., and Vijay, V. (2006). The Indian Diabetes Prevention Programme shows that lifestyle modification and metformin prevent type 2 diabetes in
Asian Indian subjects with impaired glucose tolerance (IDPP-1). Diabetologia 49, 289-297.

Rowe, D. A., Welk, G. J., Heil, D. P. Mahar, M. T., Kemble, C. D., Calabro M. A., et al. (2011). Stride rate recommendations for moderate intensity walking. Med. Sci. Sports Exerc. 43, 312-318.

Siegel, P. Z., Brackbill, R. M., and Heath, G. W. (1995). The epidemiology of walking for exercise: implications for promoting activity among sedentary groups. Am. J. Public Health 85, 706-710.

Sisson, S. B., Camhi, S. M., Church, T. S., Martin, C. K., Tudor-Locke, C., Bouchard, C., et al. (2009). Leisure time sedentary behavior, occupational/domestic physical activity, and metabolic syndrome in U.S men and women. Metab. Syndr. Relat. Disord. 7, 529-536.

Stephens, B. R., Granados, K., Zderic, T. W., Hamilton, M. T., and Braun, B. (2011). Effects of 1 day of inactivity on insulin action in healthy men and women: interaction with energy intake. Metab. Clin. Exp. 60, 941-949.

Strath, S., Swartz, A., Parker, S., Miller, N., and Cieslik, L. (2007). Walking and metabolic syndrome in older adults. J. Phys. Act. Health 4, 397-410.

Tabak, A. G., Herder, C., Rathmann, W., Brunner, E. J., and Kivimaki, M. (2012). Prediabetes: a high-risk state for diabetes development. Lance 379, 2279-2290.

The Diabetes Prevention Program Research Group. (1999). The Diabetes Prevention Program. Design and methods for a clinical trial in the prevention of type 2 diabetes. Diabetes Care 22, 623-634.

Tremblay, M. S., Colley, R. C., Saunders, T. J., Healy, G. N., and Owen, N. (2010). Physiological and health implications of a sedentary lifestyle. Appl. Physiol. Nutr. Metab. 35, 725-740.

Tremblay, M. S., Leblanc, A. G., Carson, V., Choquette, L., Connor Gorber S., Dillman, C., et al. (2012). Canadian sedentary behaviour guidelines for the early years (aged 0-4 years). Appl. Physiol. Nutr. Metab. 37, 370-380.

Tremblay, M. S., Leblanc, A. G., Janssen, I., Kho, M. E., Hicks, A., Murumets, K., et al. (2011). Canadian sedentary behaviour guidelines for children and youth. Appl. Physiol. Nutr. Metab. 36, 59-64; 65-71.

Troiano, R. P., Berrigan, D., Dodd K. W., Masse, L. C., Tilert, T. and McDowell, M. (2008). Physical activity in the United States measured by accelerometer. Med. Sci. Sports Exerc. 40, 181-188.

Tucker, J. M., Welk, G. J., and Beyler, N. K. (2011). Physical activity in U.S. adults compliance with the Physical Activity Guidelines for Americans. Am. J. Prev. Med. 40, 454-461.

Tudor-Locke, C., Craig, C. L., Brown, W. J., Clemes, S. A., De Cocker, K., Giles-Corti, B., et al. (2011a). How many steps/day are enough? For adults. Int. J. Behav. Nutr. Phys. Act. 8,79

Tudor-Locke, C., Leonardi, C., Johnson, W. D., and Katzmarzyk, P. T. (2011b). Time spent in physical activity and sedentary behaviors on the working day: the American time use survey. J. Occup. Environ. Med. 53, 1382-1387.

Tudor-Locke, C., Leonardi, C., Johnson, W. D., Katzmarzyk, P. T., and Church, T. S. (2011c). Accelerometer steps/day translation of moderateto-vigorous activity. Prev. Med. 53, 31-33.

Tudor-Locke, C., and Ham, S. A. (2008). Walking behaviors reported in the American Time Use Survey 2003-2005. J. Phys. Act. Health 5, 633-647.

Tudor-Locke, C., Ham, S. A., Macera, C. A., Ainsworth, B. E., Kirtland, K. A., Reis, J. P., et al. (2004). Descriptive epidemiology of pedometer-determined physical activity. Med. Sci. Sports Exerc. 36, 1567-1573.

Tudor-Locke, C., Johnson, J. D., and Katzmarzyk, P. T. (2010). Frequently reported activities by intensity for U.S. adults: the American Time Use Survey. Am. J. Prev. Med. 39, e13e20.

Tudor-Locke, C., Johnson, W. D., and Katzmarzyk, P. T. (2009). Accelerometer-determined steps per day in US adults. Med. Sci. Sports Exerc. 41, 1384-1391.

Tudor-Locke, C., Sisson, S. B., Collova, T., Lee, S. M., and Swan, P. D. (2005). Pedometer-determined step count guidelines for classifying walking intensity in a young ostensibly healthy population. Can. J. Appl. Physiol. 30, 666-676.

Tudor-Locke, C. (in press). Walk more (frequently, farther, faster): the perfect preventive medicine. Prev. Med.

Tudor-Locke, C., Craig, C. L., Thyfault, J. P., and Spence, J. C. (in press). A step-defined sedentary lifestyle index: < 5,000 steps/day. Appl. Physiol. Nutr. Metab.

Tuomilehto, J., Lindstrom, J., Eriksson, J. G., Valle, T. T., Hamalainen, H., 
Ilanne-Parikka, P., et al. (2001). Prevention of type 2 diabetes mellitus by changes in lifestyle among subjects with impaired glucose tolerance. N. Engl. J. Med. 344, 1343-1350.

Uusitupa, M., Louheranta, A., Lindstrom, J., Valle, T., Sundvall, J., Eriksson, J., et al. (2000). The Finnish Diabetes Prevention Study. Br. J. Nutr. 83(Suppl. 1), S137-S142.

Wang, Y., Simar, D., and Fiatarone Singh, M. A. (2009). Adaptations to exercise training within skeletal muscle in adults with type 2 diabetes or impaired glucose tolerance: a systematic review. Diabetes Metab. Res. Rev. 25, 13-40.
Weinstein, A. R., Sesso, H. D., Lee, I. M., Cook, N. R., Manson, J. E., Buring, J. E., et al. (2004). Relationship of physical activity vs body mass index with type 2 diabetes in women. JAMA 292, 1188-1194.

Westerterp, K. R. (2008). Physical activity as determinant of daily energy expenditure. Physiol. Behav. 93, 1039-1043.

Wong, S. L., Colley, R., Connor Gorber, S., and Tremblay, M. (2011). Actical accelerometer sedentary activity thresholds for adults. J. Phys. Act. Health 8, 587-591.

Wyatt, H. R., Peters, J. C., Reed, G. W., Barry, M., and Hill, J. O. (2005). A Colorado statewide survey of walking and its relation to excessive weight. Med. Sci. Sports Exerc. 37, 724-730.

Zorbas, Y. G., Yarullin, V. L. Denogradov, S. D., and Afonin, V. B. (1999). Plasma volume and biochemical changes in athletes during bed rest chronic hyperhydration. Acta Astronaut. 45, 747-754.

Conflict of Interest Statement: The authors declare that the research was conducted in the absence of any commercial or financial relationships that could be construed as a potential conflict of interest.

Received: 18 September 2012; paper pending published: 11 October 2012; accepted: 31 October 2012; published online: 19 November 2012.

Citation: Tudor-Locke $C$ and Schuna JM Jr (2012) Steps to preventing Type 2 diabetes: exercise, walk more, or sit less? Front. Endocrin. 3:142. doi: 10.3389/fendo.2012.00142

This article was submitted to Frontiers in Diabetes, a specialty of Frontiers in Endocrinology.

Copyright (c) 2012 Tudor-Locke and Schuna. This is an open-access article distributed under the terms of the Creative Commons Attribution License, which permits use, distribution and reproduction in other forums, provided the original authors and source are credited and subject to any copyright notices concerning any third-party graphics etc. 